\title{
TEACHING AND TEACHER EDUCATION
}

ELSEVIER

Teaching and Teacher Education 21 (2005) 257-272

www.elsevier.com/locate/tate

\section{Teachers' perceived efficacy among English as a foreign language teachers in middle schools in Venezuela}

\author{
Carmen Teresa Chacón \\ Department of Languages, University of Los Andes Tachira, San Cristobal, Venezuela
}

\begin{abstract}
Teachers' sense of efficacy has been shown to influence teachers' actions and student outcomes. This study explored self-efficacy beliefs among English as a Foreign Language teachers in selected schools in Venezuela. Data were collected through a survey administered to 100 teachers. The Teacher Sense of Efficacy Scale (Tschannen-Moran \& Woolfolk Hoy, 2001) was used to assess efficacy for management, engagement, and instructional strategies. Interviews were conducted with a purposeful sample. Results showed that teachers' perceived efficacy was correlated with self-reported English proficiency. Results also indicated that teachers' efficacy for instructional strategies was higher than efficacy for management and engagement.

(C) 2005 Elsevier Ltd. All rights reserved.
\end{abstract}

Keywords: Self-efficacy; Foreign language education; English as a foreign language; Middle schools; Language proficiency; Instructional strategies

\section{Introduction}

Research on teachers' beliefs and their impact on teacher cognition has been a relevant topic for educational inquiry over the last four decades. Teachers' actions and behaviors are tied to their beliefs, perceptions, assumptions, and motivation levels. Thus, research on teachers' beliefs is crucial in determining the way teachers understand and

\footnotetext{
An earlier version of this paper was presented at the Annual Meeting of the American Educational Research Association, San Diego, CA, April 2004.

E-mail address: ctchacon@cantv.net.
}

organize instruction. One important belief that appears to be an important influence on teacher and student outcomes is teachers' sense of efficacy. Pajares (1992) posited, "beliefs are formed early and tend to self-perpetuate. The earlier a belief is incorporated into the belief structure, the more difficult it is to alter" (pp. 324-325). Efficacy is likely such a belief. Teachers' perceived capabilities to teach seem to have a direct impact on teaching practices. Teachers' perceived efficacy influences not only the kind of environment they create for their students but also their judgments about the different tasks they perform to bring about student learning (Bandura, 1993, 1997). The 
present study focused on teacher self-efficacy beliefs in the context of EFL classrooms, taking into account that both teaching tasks and teachers' assessment of their capabilities form part of efficacy beliefs (Tschannen-Moran, Woolfolk Hoy, \& Hoy, 1998). In this study, teachers' sense of efficacy refers to English teachers' judgments on their capabilities to bring about student change even in those difficult or unmotivated students (Gibson \& Dembo, 1984; Guskey \& Passaro, 1994).

\section{Theoretical framework}

According to Bandura (1993, 1997), teachers' beliefs in their instructional efficacy influence the kind of learning environment they create to orchestrate learning. Teachers with a high sense of teaching efficacy believe that difficult students can be teachable if the teacher puts extra effort. Conversely, teachers with a low sense of teaching efficacy believe that there is little they can do to teach unmotivated students because students' success depends on the external environment (Gibson \& Dembo, 1984). Bandura (1997) pointed out:

teachers who believe strongly in their ability to promote learning create mastery experiences for their students, but those beset by self-doubts about their instructional efficacy construct classroom environments that are likely to undermine students' judgments of their abilities and their cognitive development. (p. 241)

In Bandura's words, teachers' sense of efficacy is reciprocally determined for it affects teachers' behavior and pedagogical actions as well as their perceptions of the consequences of such actions.

Over the two decades of research on teachers' sense of efficacy, findings (Coladarci, 1992; Gibson \& Dembo, 1984; Riggs \& Enochs, 1990; Soodak \& Podell, 1997; Woolfolk \& Hoy, 1990; Woolfolk, Rosoff, \& Hoy, 1990) support at least two separate dimensions of teachers' perceived efficacy: Personal Teaching Efficacy (PTE) (a teacher's belief that he or she can impact student learning) and Teaching Efficacy (a teacher's belief that the profession in general brings about student change) later called General Teaching Efficacy (GTE). Grounded in Bandura's conceptualization of selfefficacy, researchers (Emmer \& Hickman, 1990; Tschannen-Moran \& Woolfolk Hoy, 2001; Tschannen-Moran, Woolfolk Hoy, \& Hoy, 1998; Woolfolk et al., 1990) argue that teacher efficacy is multidimensional, subject-matter specific, and therefore, varies across tasks. Thus, researchers claim that teacher efficacy should be examined in terms of tasks and specific contexts. Although a growing number of studies have investigated teacher efficacy in different subject matters (e.g., mathematics and science), little research has been conducted to explore the perceived efficacy of teachers of English in contexts outside the US Tschannen-Moran et al. asserted that teacher efficacy is constructed based on personal knowledge and beliefs but also on the impact exerted by culture and society on the teachers' expectations, roles, and social relations. Therefore, there is a need to examine teachers' perceptions of their teaching competence in terms of personal capabilities to teach English as a Foreign Language (EFL).

\subsection{Sources of efficacy}

Bandura (1977, 1997) stated that individuals construct their self-efficacy from four sources of information: (a) Enactive mastery experiences (performance accomplishment). Efficacy beliefs are generated from successes and failures when performing a task (Bandura, 1997). Success tends to strengthen beliefs in one's efficacy whereas failures tend to weaken them. (b) Vicarious learning experiences (modeling). Observing others perform a task helps people evaluate in terms of observation their abilities to perform the same task. Bandura (1997) posited that while observing others' attainments, individuals compare themselves as performers in the same situation. (c) Verbal persuasion. When people receive realistic appraisals from their significant others, i.e., "evaluative feedback" (Bandura, 1997, p. 101) in the form of verbal persuasion, regarding their attainments, individuals seem to strengthen their beliefs on the capabilities they have to achieve 
what they want. (d) Physiological arousal. Affective states influence people's beliefs of self-efficacy. Physiological arousal in the form of mood, stress, and subjective threats affects people performance.

\subsection{Factors associated with teachers' sense of efficacy}

Research conducted over the past three decades has found that teachers' self-efficacy affects student achievement and motivation (Gibson \& Dembo, 1984), teachers' adoption of innovation (Ghaith \& Yaghi, 1997; Guskey, 1988), commitment to teaching (Coladarci, 1992), teachers' classroom management and control strategies (Woolfolk \& Hoy, 1990; Woolfolk et al., 1990), and teachers' personal characteristics such as gender, grade level taught and experience (Ghaith \& Shaaban, 1999; Ross, Cousins, \& Gadalla, 1996).

\subsubsection{Teachers' sense of efficacy and student achievement}

Gibson and Dembo's (1984) study of teachers' self-efficacy identified significant differences between high efficacious and low efficacious teachers. High efficacious teachers persisted with low achieving students, made better use of time, criticized students' incorrect answers less, and were more effective in guiding students to correct answers through their questioning. Low efficacy teachers, on the other hand, spent more time in nonacademic activities and made use of less effective techniques to guide students to correct responses.

\subsubsection{Teachers' sense of efficacy and teachers' commitment \\ Coladarci (1992) found that PTE and GTE} "were the two strongest predictors of commitment to teaching" (p. 334). His findings suggested that teachers who were more confident in their abilities to affect student achievement through teaching, and who assumed personal responsibility for influencing student achievement, tended to have a higher commitment to teaching.

\subsubsection{Teachers' sense of efficacy and adoption of innovation}

Research in teachers' perceived efficacy has examined teacher efficacy in relation to teachers' willingness to introduce innovation in their teaching practice. Guskey's (1988) study found that teachers with greater personal efficacy had also positive attitudes towards teaching (teaching affect) and had a fairly high level of confidence in their teaching abilities (teaching self-concept). In other words, those who liked teaching and felt confident about their abilities were highly effective in the classroom and seemed to be the most receptive to implement new practices. Conversely, those assumed to be less effective appeared to be the least receptive to innovation (p. 67).

\subsubsection{Teachers' sense of efficacy and experience}

Other researchers (Guskey, 1984, 1988; Pajares, 1992; Woolfolk Hoy \& Murphy, 2001) have found that experienced teachers' beliefs of efficacy tend to be "stable" and hard to change once they have been established. Soodak and Podell's (1997) study examined how preservice and experienced teachers developed perceptions of their capabilities over time. They found no significant changes in the personal efficacy beliefs among high school teachers while elementary teachers experienced a dramatic drop in their personal efficacy as they started their first year of teaching. That is, preservice teachers' personal teaching efficacy (PTE) was initially high during their fieldwork and student teaching, but it declined "precipitously" (p. 219) during their first year of teaching. This finding suggests that experienced teachers beliefs of personal efficacy are more resistant to change.

\subsubsection{Teachers' sense of efficacy and classroom management}

Woolfolk et al.'s (1990) study among practicing teachers found that those teachers with a great sense of PTE (beliefs in their abilities to reach students) and GTE (beliefs that all students can be taught) tended to be humanistic rather than custodial. In other words, the more efficacious the teacher, the less custodial to control students 
and the more likely he or she seemed to support student autonomy and responsibility.

In another study Woolfolk and Hoy (1990) examined prospective teachers' sense of efficacy, pupil control ideology, motivational orientation, and bureaucratic orientation. They found that teachers with high efficacy were more humanistic in their pupil control than teachers with low efficacy, who tended to be custodial, i.e., more authoritarian and dogmatic. In other words, teachers with a custodial orientation were more rigid and highly controlled students while teachers with a humanistic orientation tended to emphasize cooperation, interaction, and experience as well as student autonomy.

\subsection{The teaching of EFL in Venezuela}

In Venezuela, as in many countries around the world, English is taught as a foreign language, and it is one of the required academic courses in the National Curriculum in order to earn a high school diploma. According to the Ministry of Education, (Ministerio de Educación, 1987) students are required to study English in junior and senior high school based on the need of being able to use English as a means of communicating with people from English speaking countries and being able to read and understand English to have access to journals, magazines, and books written in English (p. 18, author's translation). The orientation towards communicative language teaching (CLT) was introduced by the Venezuelan Ministry of Education in 1987. Larsen-Freeman (2000) explains that "CLT aims broadly to apply the theoretical perspective of the communicative approach by making communicative competence the goal of language teaching and by acknowledging the interdependence of language and communication" (p. 121). Thus, Venezuelan students in high school are expected to acquire the communicative competence that enables them to use English as a vehicle of communication.

The rationale for using CLT is based on the need to use the language for communicative purposes that implies a shift from teaching accuracy (grammar rules and translation) to focus on language as meaning. A major principle in CLT is to use language forms in different contexts and for variety of purposes. Therefore, grammar must be taught in context so that students use the language as a tool to create meaningful messages. Activities in CLT involve the use of strategies that engage students in social interaction (e.g., dialogues, simulations, games, debates, and problem solving).

However, the implementation of CLT requires EFL teachers who possess the competency of the language in order to teach it. It is expected that EFL teachers use CLT in EFL classes, which requires the ability to understand, speak, read, and write English with functional ability in communicating across the language skills (Savignon, 1983, 2002). Working on this principle, Lafayette (1993) states that "Among the components of content knowledge, none is more important to foreign language teaching than language proficiency" (p. 135). According to ACTFL (American Council on the Teaching of Foreign Languages), the foreign language teacher should be able to hear, understand, speak, read, and write in the target language with a minimum level of proficiency either advanced or advanced high. From this perspective, language fluency should be a major concern in all teacher education programs, and as Lafayette asserts "university foreign language faculty have an obligation to model good teaching, which first and foremost implies use of the target language as the vehicle of instruction" (p. 137).

As mentioned before, the goal for learning English in Venezuela is to use the language for communicative purposes. Therefore, teacher education programs are in charge of developing teachers' competency in English. In Venezuela, upon graduation EFL teachers are hired to teach in high schools without having to pass any exam that shows their English competency; administrators do not require teachers to obtain an additional certification to teach English.

Even though teachers' competence in the target language is a requirement to use CLT, researchers in the field (Crandall, 1999; Freeman, 1989; Tedick $\&$ Walker, 1995) have found that the education of EFL teachers tends to focus on theoretical pedagogical knowledge and on English language 
skills based on grammar, phonology, morphology, syntax, and lexicon of the language, and more recently in notions and functions. In this sense, it is not surprising that teacher education programs in Venezuela, for example, place a heavy emphasis on descriptive linguistics, i.e., the study of the language at the sentence level (Chacón, Alvarez, Brutt-Griffler, \& Samimy, 2003), overlooking the social nature of language as a means of communication and interaction.

Thus, subject matter knowledge, particularly language proficiency, is critical in foreign language teaching. Some scholars (Brosh, 1996; Crandall, 1999; Lafayette, 1993; Lange, 1990) argue against the pervasive tendency in many foreign language teacher education programs to view language as an "object" (Tedick \& Walker, 1995) where instruction often becomes fragmented, decontextualized, teacher-centered, and separated from students' needs and interests (Cullen, 1994). As a result, generally teachers in Venezuela, for instance, may not acquire the communicative competence to perform in the four language skills: speaking, listening, reading, and writing. Without this competency, teachers find themselves unable to use CLT in their English classes ( $\mathrm{Li}, 1998)$ as they do not judge themselves competent in English (e.g., speaking) and therefore, they tend to build a low sense of efficacy.

\subsection{English teacher education in Venezuela}

As in most Venezuelan universities, the English language teacher education program at one of the largest universities in the western part of the country is a 5-year program that prepares teachers who want to major in English. Students obtain the degree of Licenciate in Education, Teaching Major: English. The requirements to enter the program are limited to a high school diploma and a GPA of 12 points. The scale is from 0 to 20 . The lowest passing grade is 10 . There is no established assessing or testing instrument as a requirement to evaluate students' English proficiency or language aptitude before they enter the program. In 1996, the program that had started in 1974 underwent a major curricular reform. The traditional ninesemester program was gradually replaced by a 5- year program. Nonetheless, regarding the specialist component, the curriculum did not change much. The curriculum was, and still is mostly concentrated on developing prospective teachers' pedagogical knowledge. Around $65 \%$ of the course work deals with pedagogy and field experiences while approximately $35 \%$ entails the subject matter knowledge (i.e., acquisition of the English communicative competence).

The present study explored the sense of efficacy for teaching among a group of EFL Venezuelan middle school teachers. English self-reported proficiency and self-reported use of pedagogical strategies to teach were examined. The following research questions were addressed in this investigation:

1. What are the levels of self-reported efficacy beliefs for engagement, classroom management, and instructional strategies among EFL teachers in selected middle schools in Venezuela?

2. What do teachers report to be their English proficiency level in listening, speaking, reading, writing, and culture knowledge?

3. What pedagogical strategies do teachers use to teach EFL?

4. What are the correlations among EFL teachers' sense of efficacy for engagement, classroom management, and instructional strategies and reported English proficiency, use of pedagogical strategies, and demographic variables such as years of English experience, experience studying/traveling abroad, and staff development?

\section{Methodology}

The present study included both descriptive and correlational analyses as well as interviews with a purposeful sample. Descriptive statistics, including means, variances, and item-total correlations were computed for every item. Pearson's product moment-correlation coefficient $r$ was computed between the dependent variable (teacher efficacy) and the independent variables (self-reported English proficiency, self-reported use of strategies to teach, years teaching English, experiences studying 
or visiting English-speaking countries, and staff development).

\subsection{Participants}

The population of this study comprised EFL middle school teachers within one large urban school district in the western part of Venezuela. Fifty-one high schools represented the accessible population $(N=104)$ of EFL teachers. The researcher conducted a census on the population selected by obtaining an up-to-date listing provided by the Ministry of Education, which was double checked in each school to avoid duplication of names. Surveys were researcher administered in the teachers' site of work. Four teachers were on leave at the time the surveys were applied. The results of the present study will not be generalized beyond the actual population; therefore, external validity will not be considered a major concern for the outcome measures.

From the population $(N=100), 60 \%$ were females, $30 \%$ males and $4 \%$ no indication. Forty percent of the respondents have been teaching for 6-12 years. Twenty-six percent reported teaching between 13 and 20 years while other $26 \%$ reported having less than 5 years of experience. A small percentage $(8 \%)$ reported more than 20 years of teaching experience. Eighty-four percent of the respondents held a Bachelor's degree in Education with a major in English, whereas $8 \%$ held a Master's Degree not related to the field of applied linguistics or foreign second language education. A low percentage $(3 \%)$ held a specialization in elementary school teaching. Twenty-two percent had experience studying or traveling to Englishspeaking countries while $77 \%$ did not have that experience. Of the participants, $54 \%$ never attended staff development while $30 \%$ attended once a year, and $12 \%$ between $2-3$ times a year.

\subsection{Instrument}

The instrument hereafter called English Teachers' Sense of Efficacy Scale (ETSES) comprised five subscales: (a) teachers' perceived efficacy for engaging students in learning EFL, (b) teachers' perceived efficacy for managing EFL classes, (c) teachers' perceived efficacy for implementing instructional strategies to teach EFL, (d) teachers' self-reported English proficiency, and (e) teachers' self-reported pedagogical strategies to teach English (communication-oriented and grammar-oriented strategies). The instrument also included EFL teachers' demographic characteristics (years of experience teaching English, staff development experiences, and experience traveling/studying into English-speaking countries).

\subsubsection{Efficacy for engagement, classroom management, and instructional strategies}

The short version of the Teacher Sense of Efficacy Scale (Tschannen-Moran \& Woolfolk Hoy, 2001) was adapted to fit the context of EFL by adding or substituting "English" or "learning English" for "school work" in items 1, 2, 3, 4, 6, 7, 9, 10, and 12. The TSES consists of 12 items including four items for each of the three subscales: efficacy for engagement, efficacy for management, and efficacy for instructional strategies. The items measuring "how much an individual can do" in regards to efficacy for engagement, efficacy for management, and efficacy for instructional strategies use a 9-point scale with anchors at 1 -nothing, 3-very little, 5-some influence, 7quite a bit, and 9-a great deal. Sample items were "How much can you do to control disruptive behavior in your English class?" (Efficacy for management); "How much can you do to motivate students who show low interest in learning English?" (Efficacy for engagement); and "How much can you use a variety of assessment strategies in your English class?" (Efficacy for instructional strategies) (see Table 1).

\subsubsection{Teachers' self-reported proficiency}

The measure for English proficiency assessed the participants' self-reported proficiency of English to communicate written and oral messages appropriate to specific situations since they are expected to use CLT in their EFL classes as already mentioned. Sixteen items based on the professional literature and the researcher's experience constituted the measure of self-reported level of English proficiency (see Table 2). The items were 6-point Likert-type, ranging from "Strongly Agree" (6) to 
Table 1

Means and standard deviations of teachers' sense of efficacy

\begin{tabular}{|c|c|c|}
\hline Efficacy subscales & $M$ & $S D$ \\
\hline \multicolumn{3}{|l|}{ Efficacy for engagement } \\
\hline How much can you do to motivate students who show low interest in learning English? & 6.62 & 1.61 \\
\hline How much can you do to get students to believe they can do well in English? & 7.07 & 1.43 \\
\hline How much can you do to help your students' value learning English? & 6.95 & 1.45 \\
\hline How much can you assist families in helping their children do well in school? & 5.72 & 2.06 \\
\hline Total & 6.59 & 1.3 \\
\hline \multicolumn{3}{|l|}{ Efficacy for management } \\
\hline How much can you do to control disruptive behavior in the classroom? & 6.77 & 1.72 \\
\hline How much can you do to get students to follow classroom rules in your English classroom? & 7.32 & 1.34 \\
\hline How much can you do to calm a student who is disruptive or noisy in your English class? & 7.05 & 1.48 \\
\hline How well can you establish a classroom management system with each group of students? & 6.89 & 1.37 \\
\hline Total & 7 & 1.21 \\
\hline \multicolumn{3}{|l|}{ Efficacy for instructional strategies } \\
\hline How much can you use a variety of assessment strategies in your English class? & 7.23 & 1.56 \\
\hline To what extent can you provide an alternative explanation or example when your English students are confused? & 7.46 & 1.48 \\
\hline To what extent can you craft good questions for your students? & 6.85 & 1.58 \\
\hline How well can you implement alternative strategies in your English classroom? & 7 & 1.6 \\
\hline Total & 7.13 & 1.22 \\
\hline
\end{tabular}

Table 2

Means and standard deviations of English proficiency

\begin{tabular}{lc}
\hline English skills & $M$ \\
\hline I can understand magazines, newspapers, and popular novels when I read them in English. & 4.77 \\
I can draw inferences/conclusions from what I read in English. & 0.98 \\
I can figure out the meaning of unknown words in English from the context. & 0.83 \\
I can write business and personal letters in English without errors that interfere the meaning I want to convey. & 4.32 \\
I can write a short essay in English on a topic of my knowledge. & 0.74 \\
I can fill in different kinds of applications in English (e.g., credit card applications). & 1.1 \\
I can understand when two English-speakers talk at a normal speed. & 4.86 \\
I understand English films without subtitles. & 0.82 \\
I can understand a message in English on an answering machine. & 0.88 \\
In face-to-face interaction with an English-speaker, I can participate in a conversation at a normal speed. & 3.83 \\
I can express and support my opinions in English when speaking about general topics. & 1.2 \\
I understand the meaning of common idiomatic expressions used by English-speakers. & 4.47 \\
I know the necessary strategies to help maintain a conversation with an English-speaker. & 4.11 \\
I can talk in English about cultural themes and norms in the US & 1.1 \\
I know how to act in social English-speaking situations. & 4.25 \\
I know the English terms to use in regular classroom interaction with students. & 1.1 \\
\hline
\end{tabular}

"Strongly Disagree" (1). The higher the score, the more proficient teachers self-reported themselves in reading, writing, listening, speaking, and culture knowledge in English. Examples of these measures were: "I can understand a message in English on an answering machine" (listening), "In face-toface interaction with an English speaker, I can participate in a conversation at normal speed" 
(speaking), "I can draw inferences/conclusions from what I read in English" (reading), "I can write a short essay in English on a topic of my knowledge" (writing), and "I know how to act in social English-speaking situations" (culture).

\subsubsection{EFL teachers' self-reported pedagogical strategies}

Pedagogical strategies included teaching routines, procedures, tasks, and materials regularly used to facilitate student learning in the English class. To assess the pedagogical strategies used in their classrooms, participants were asked to rate their response from 6 to 1 on a Likert-type scale ranging from "Almost always" (6) to "Almost never" (1). Eleven statements based on the professional literature (Brown, 1994; Freeman, 1989; Nunan, 1995; Savignon, 1983, 2002) were developed to assess the pedagogical strategies to teach English. Of the 11 items, 6 items identified strategies mainly used in teaching EFL through the grammar-translation method. An example of a grammar-translation item was "Students copy grammar exercises from the blackboard after the teacher's explanation." The other five items addressed strategies used to teach EFL through CLT. Under CLT, negotiation of meaning is a major component in the tasks designed to facilitate students' acquisition of communicative competence (Savignon, 2002). An example of this type of item was "Students pair off to discuss answers to problem-solving situations/activities."

Reliability of the instrument was assessed by using Cronbach alpha coefficient, which resulted in .79 for efficacy in engagement, .83 for management, .81 for instructional strategies, .92 for English proficiency, and .80 for pedagogical strategies.

\section{Results}

\subsection{Self-efficacy beliefs for engagement, management, and instructional strategies}

The descriptive statistics for self-reported efficacy for management, instructional strategies, and engagement are shown in Table 1 . The means in the three subscales suggest that participants judged themselves more efficacious for instructional strategies $(M=7.13)$ than for management $(M=7.00)$ and engagement $(M=6.59)$. In light of Bandura's theory and Tschannen-Moran et al.'s model this finding indicates that the participants' judged their abilities to motivate students to learn English as low while they perceived themselves more capable in designing instructional strategies, providing explanations, and assessing students as well as in managing student behavior.

\subsection{Self-reported English proficiency}

Table 2 presents the means and standard deviations for each of the 16 items measuring English competency. Data showed that for reading, "Figuring out the meaning of unknown words in English from the context" was the easiest item $(M=4.90)$. For writing, "Filling out different applications in English (e.g., a credit card application)" had a high mean $(M=4.87)$. As for listening skills, teachers self-reported less proficient in understanding English films without subtitles $(M=3.88)$. For speaking skills, they rated themselves less proficient in understanding the meaning of common idiomatic expressions used by native speakers $(M=4.04)$. Their cultural knowledge $(M=3.71)$ and strategic competence $(M=3.87)$ were self-reported with low means. In contrast, participants rated their knowledge of the English terms used in regular classroom interactions with students with the highest mean $(M=5.00)$. Overall, teachers reported more difficulty with spoken English (listening and maintaining a conversation) and with cultural knowledge and strategic competence. On the other hand, participants rated more proficient in reading and writing skills.

\subsection{Correlations among EFL teachers sense of efficacy and self-reported English proficiency, pedagogical strategies and demographic characteristics}

The Pearson product-moment correlation coefficient (see Table 3) indicating the relationships among EFL teachers' sense of efficacy and the 
Table 3

Correlations among self-efficacy subscales and other variables

\begin{tabular}{llllllllllll}
\hline Variable & $\begin{array}{c}\text { Comm. } \\
\text { strategy }\end{array}$ & Grammar-strategy & Speak & Listen & Read & Write & Culture & $\begin{array}{l}\text { Years } \\
\text { exper. }\end{array}$ & $\begin{array}{l}\text { Study } \\
\text { abroad }\end{array}$ & $\begin{array}{l}\text { Staff } \\
\text { develop. }\end{array}$ \\
\hline Efficacy for engage. & 0.39 & 0.24 & 0.34 & 0.29 & 0.26 & 0.3 & 0.3 & -0.17 & 0.08 & 0.23 \\
Efficacy for instruc. strategy & 0.32 & 0.24 & 0.39 & 0.34 & 0.41 & 0.38 & 0.33 & -0.06 & 0.03 & 0.25 \\
Efficacy for manage. & 0.26 & 0.24 & 0.17 & 0.1 & 0.08 & 0.23 & 0.14 & -0.08 & -0.02 & 0.18 \\
\hline
\end{tabular}

variables of the study are discussed in the next section.

\subsubsection{Self-efficacy and English proficiency}

Positive correlations were found between Venezuelan EFL teachers' self-reported proficiency in listening, speaking, reading, writing, and culture knowledge and their sense of efficacy for engagement and for instructional strategies (see Table 3) whereas no correlations except for writing were found with efficacy for management. These results reveal that the more proficient in the language skills the teachers rated themselves, the higher their self-efficacy to engage students and orchestrate instructional strategies to teach them. In other words, perceived efficacy for motivating students and for designing instructional strategies seems to increase as language proficiency increases. With regard to the relationship between writing and efficacy for management a positive correlation $(r=.23)$ was found, which suggests that the higher the teachers' writing proficiency, the higher their sense of efficacy for managing students. Efficacy for managing students was not associated with speaking, listening, reading, and culture.

\subsubsection{Self-efficacy and classroom strategies}

The relationship between teachers' self-efficacy and instructional strategies was found to be positive. Communication-oriented strategies correlated with self-efficacy for engagement $(r=.39)$, management $(r=.26)$, and instructional strategies $(r=.32)$. Grammar-oriented strategies were also positively correlated with teachers' sense of efficacy for engagement $(r=.24)$, for management $(r=.24)$ and for instructional strategies $(r=.24)$.
Table 4

Means difference between communication-oriented and grammar-oriented strategies

\begin{tabular}{lllll}
\hline & $M$ & $S D$ & Mean difference & $t^{*}$ \\
\hline Communication & 3.594 & 0.98163 & & \\
Grammar & 4.2533 & 0.84003 & -0.6593 & -7.364 \\
\hline${ }^{*} p<.001$. & & & &
\end{tabular}

These findings suggest that the higher the participants' sense of efficacy the more likely they were to use either communication-oriented or grammaroriented strategies. As it can be seen, perceived efficacy did not seem to influence whether they chose communication-oriented or grammar-oriented strategies. However, when a pair-sample $t$ test (see Table 4) was run, it revealed a statistically significant difference between both type of strategies $(t=-7.364 ; p<.001)$ indicating that although teachers' use of strategies was not mutually exclusive, they seemed to be more oriented towards the use of strategies consistent with the grammar-translation method (e.g., lectures with explanations and demonstrations, deductive grammar, translation). Overall, grammar-oriented strategies had a higher mean $(M=4.25)$ than communication-oriented strategies $(M=3.59)$. Despite the fact that teachers in Venezuela should use CLT to teach English, research (Chacón, 2003) has found that the grammar-translation method is predominantly used among a majority of high school teachers. This finding supports studies conducted in other foreign contexts where a number of EFL teachers exhibit lack of oral proficiency ( $\mathrm{Li}, 1998)$. 


\subsubsection{Self-efficacy and selected demographic characteristics}

Years of teaching English: Data showed that there were not correlations between perceived efficacy for engagement, instructional strategies, and management and years of English teaching experience (see Table 3). This result corroborates previous research (Guskey, 1984; Pajares, 1992) that found that efficacy beliefs of practicing teachers tend to be stable as they grow in years of experience.

Traveling or studying abroad: Teachers' experiences traveling or studying in English-speaking countries were not associated with the levels of self-efficacy for engagement, instructional strategies, and management.

Staff- development: Staff development and teachers' self-efficacy for engagement and instructional strategies were correlated while no correlation was found between perceived efficacy for management and staff development. Thus, the more in-service training the teachers reported having, the higher their efficacy to design instructional strategies and to engage students in learning English.

In sum, positive correlations among English proficiency and self-efficacy for engagement and for instructional strategies suggest that it is critical to provide EFL teachers with mastery experiences that help them build a stronger sense of efficacy in the language skills as well as in their capabilities to use CLT to foster social interaction. Statistical analyses indicate that the use of pedagogical strategies was not mutually exclusive, but teachers tended to rely more on accuracy (grammar) than on communication. With regard to demographic variables, only staff development was found to be positively correlated with participants' self-efficacy for engagement and for instructional strategies. This finding is important in the context of the present study because $54 \%$ of the participants reported that they had never attended staff development. No correlations were found between teachers' perceived efficacy and years of experience, which supports previous studies about the stability of practicing teachers' efficacy beliefs. Traveling or studying into English-speaking countries was not associated with the participants' self-efficacy.

\subsection{Interviews with a purposeful sample}

The next section reports data gathered through individual interviews with a purposeful sampling of 20 participants selected out of the 65 who volunteered after the survey was applied. Summated scores of the items measuring efficacy for engagement, management, and instructional strategies were used to select interviewees who scored the highest and lowest in the three efficacy subscales. Using the "maximum variation sampling" (Seidman, 1998, p. 45), the researcher selected among teachers who worked in public and private schools, represented males and females, had different ranges of teaching experience, and experience studying or traveling into English-speaking countries. Detailed information about the subjects' background is given in Tables 5 and 6. Tape-recorded interviews in Spanish lasted from $45 \mathrm{~min}$ to an hour and were transcribed for the analysis. The participants' anonymity was assured by assigning them different names.

Four short vignettes (see Appendix A) describing four strategies (a dialogue, a song, a simulation, and a problem solving) being applied in four different classrooms were used to have the participants indirectly talk and discuss what the best strategy to teach EFL would be for the participants. In addition, the researcher used semistructured open-ended questions (Spradley, 1979) throughout the interview in order to interpret each interviewee's point of view. Examples were: "What do you think about the strategy being used by these EFL teachers?" "How could your students have reacted to the same strategy?" "What would you anticipate that may happen?"

\subsection{Analysis of the data from the interviews}

Through cross comparison among the respondents' answers, common patterns about the interviewees' perceptions were identified. Both high efficacious as well as low efficacious teachers chose Classroom 1, 2, and 3 (see Appendix A) to comment on the strategies being portrayed in each vignette. None of them, however, chose vignette 4 where a teacher was using problem-solving as a strategy to have students use English as the vehicle 
Table 5

High efficacy group characteristics

\begin{tabular}{|c|c|c|c|c|}
\hline Subject & Degree earned & $\begin{array}{l}\text { Experience teaching } \\
\text { English (in years) }\end{array}$ & Staff development & $\begin{array}{l}\text { Experience traveling/ } \\
\text { studying abroad }\end{array}$ \\
\hline Ana & B. A & $6-12$ & Never & Yes \\
\hline Beatriz & $\begin{array}{l}\text { M.A Management in } \\
\text { Ed. }\end{array}$ & $6-12$ & Once a year & No \\
\hline Cristina & B.A & $6-12$ & Never & Yes \\
\hline Danilo & B. A & $6-12$ & Never & No \\
\hline Joana & B.A & Less than 5 & Once a year & No \\
\hline Kiko & B.A & Less than 5 & Once a year & No \\
\hline Leida & B.A & Less than 5 & Twice a year & No \\
\hline Maria & B.A & $13-20$ & Once a year & No \\
\hline Nancy & B.A & $6-12$ & Once a year & Yes \\
\hline Octavio & B.A & $6-12$ & Twice a year & Yes \\
\hline Pedro & B.A & Less than 5 & Once a year & No \\
\hline
\end{tabular}

Table 6

Low efficacy group characteristics

\begin{tabular}{lllll}
\hline Subject & Degree earned & $\begin{array}{l}\text { Experience teaching } \\
\text { English (in years) }\end{array}$ & Staff development & $\begin{array}{c}\text { Experience traveling/ } \\
\text { studying abroad }\end{array}$ \\
\hline Eva & B.A & More than 20 & Once a year & Yes \\
Flor & B.A & $6-12$ & Once a year & No \\
Gloria & B.A & Less than 5 & Once a year & No \\
Helena & B.A & Less than 5 & Never & No \\
Ileana & M.A Adult education & $13-20$ & Once a year & No \\
Quintero & B. A & Less than 5 & Never & Yes \\
Rosa & M.A College & $6-12$ & Never & No \\
Sara & instruction & $13-20$ & Once a year & No \\
Tomas & B.A & Less than 5 & Never & \\
\hline
\end{tabular}

of communication to discuss and find answers to a particular situation. Next, interpretation of the data with quotations from respondents is presented.

High efficacious teachers commented on the use of dialogues (vignette 1) as a common practice to approach the EFL class. Data ${ }^{1}$ from the interviews suggest that the dialogue is generally taken from the textbook, modeled so that students repeat right after the teacher, then translate it, and perform it in class. In her words, Cristina said, "I select a

\footnotetext{
${ }^{1}$ The original data are all in Spanish. In translating the teachers' quotations, I made sure to preserve the meaning of the quotation as much as possible.
}

dialogue from the textbook and then we read together and practice the difficult words. We practice many times. Then, students try to memorize the dialogue by repeating it several times." Danilo also relied on drilling and translation to present the dialogue. He explained, "I read the dialogue two or three times. Then, I have students repeat right after me. After, I ask two students to role-play the dialogue. I translate what the students don't know." Although dialogues can be used as a strategy to foster communication, the participants used dialogues oriented towards emphasis on modeling, accuracy, and memorization of structures that lead to language acquisition as habit formation (Brown, 1994). 
Among the high efficacious teachers, the use of the grammar-translation method to teach English was a common pattern. As Kiko put it, "Before practicing a dialogue, I first explain everything that has to do with grammar structures and rules, that sort of things, and then, once it is clear, we apply that knowledge to understand the dialogue." The study of the language through grammar rules taught deductively and using the students' native language as the medium of instruction are popular tenets consistent with the grammar-translation approach.

Low efficacious teachers, on the other hand, also used dialogues and emphasized grammar explanations, pattern practice, and translation of new vocabulary items focusing on accuracy and memorization. In her interview, Helena expressed, "I also use dialogues as an important strategy to teach English. Well, in translation, I also make emphasis. I have students repeat chorally and individually and learn the meaning of words." Grammar-oriented strategies were predominantly used among low efficacious and high efficacious teachers; perceived efficacy did not seem to have direct impact on whether teachers used CLT or the grammar-translation method. Cross-comparison among the participants' responses indicates that grammar explanations provide the rules students need to put words together. The new material is presented in a dialogue form, but the focus is not on communicative activities, but on pattern practice. Referring to vignette 1, Quintero elaborating on the use of textbooks expressed his concern about grammar teaching. He said,

Textbooks do not explain the necessary grammar students require before they are able to do the exercises. I give them [students] the explanation the textbook lacks because before a kid can do the exercises, he needs to know grammar.

In this sense, it is important to note that language learning entails much more than repeating and memorizing structures and applying rules. Over the years, research in the field of second/ foreign language acquisition has shown that although learners can do well in drills they fail to make the transition to communicate in real life.
The above quotes suggest that both high and low efficacious teachers tend to favor strategies that are consistent with the "traditional" methodology for foreign language teaching. Through this perspective, students learn about the language, but are unable to use it as a means to communicate, share information, negotiate meaning, and interact, which are major principles of the CLT approach. Yet using the CLT approach does not imply to abandon the teaching of grammar, an important tenet of CLT is to engage students in "activities involving real communication; carrying out meaningful tasks; and using the language which is meaningful to the learner" (Brown, 1994, p. 70). In sum, data from the interviews show that participants place emphasis on accuracy over meaning. Most of them reported teaching grammar and having students drill and memorize dialogues that were generally role played in class.

\subsubsection{Teachers' sense of efficacy and teachers' proficiency in English}

While literature about teacher efficacy and language proficiency in EFL is scarce, this study found positive correlations between teachers' selfreported English proficiency and efficacy for engagement and instructional strategies. During the interviews teachers commented about their English proficiency. Interestingly enough, they talked about their lack of confidence in their abilities to speak English. At least $50 \%$ of the interviewees (including high efficacious and low efficacious teachers) reported deficiencies in spoken English. For instance, Helena from the group of low efficacious teachers expressed:

I like to teach. One thing I can't deny though is that, I can't speak English perfectly. I feel bad about it. Sometimes my students don't understand me, and I think it's because I may not be pronouncing well so I switch to Spanish.

Among the high efficacious teachers, Danilo echoes Helena's perceptions regarding English proficiency. In his words, "the problem would be that I don't have the proficiency level for conversational English. Although I try to improve my pronunciation through English courses, I think that my spoken deficiencies limit my fluency." 
Principles underpinning CLT require EFL teachers to be fluent in English; however, this study found that teachers reported limitations in speaking and listening while they rated more proficient in reading and writing skills. These findings suggest that EFL teachers may not always be competent to speak English, which becomes a constraint to implement CLT in high schools. While CLT demands teachers to be proficient in English, the grammar-translation method "requires few specialized skills on the part of teachers. Tests of grammar rules and of translations are easy to construct and can be objectively scored" (Brown, 1994, p. 53). As a result, EFL teachers approach the study of the language through grammar rules and habit formation. There would appear to be a tendency to overcome lack of fluency in the language by focusing on the theoretical knowledge about the language. As Tomas said, "Teachers feel more comfortable teaching grammar than speaking in English. In teaching grammar, there is less probability to make mistakes than speaking in English; rules and formulas never change." Likewise, Pedro acknowledged the fact that teachers judge themselves more confident in teaching grammar. In his own words, he expressed, "Teachers graduate with a good command of grammar. I can't complain about that, but when it comes to speak the language there is no much experience. So teachers end up overwhelming kids with formal grammar; teaching becomes mechanical." According to these results, it is likely that the lack of fluency affects teachers' judgments about their capability to speak English making them focus on grammar and preventing them from orchestrating mastery experiences that foster real life communication. This finding is consistent with previous research (Chacón, 2003; Li, 1998; Sato \& Kleinsasser, 1999; Sato, 2002) that suggests that one reason why EFL teachers tend to focus on grammar is because of lack of confidence in their oral skills.

\section{Discussion}

Means computed for the three subscales measuring efficacy revealed that the participants judged their capabilities for instructional strategies as higher than their capabilities for engagement and for classroom management. Statistical analysis showed the participants' tendency towards grammar-oriented strategies. Data from the interviews seem to support quantitative analyses as the majority of interviewees reported using more grammar-oriented strategies (accuracy) than strategies conducive to communication (meaning). In regard to language proficiency, statistical analyses showed low means for listening, speaking, and culture knowledge that suggest language deficiencies. Additionally, during the interviews, the majority of interviewees expressed concern about deficiencies in spoken English. Furthermore, results also showed that English language skills were positively correlated with teachers' sense of efficacy. In other words, the higher the teachers' perceived efficacy in the language skills (speaking, listening, writing, and reading), the higher their sense of efficacy to motivate students and to design instructional strategies. In this sense, it is important to note that EFL teachers' confidence about their capabilities to teach English affects their perceived efficacy to bring about student change. Lack of competency in English influences teachers' self-efficacy because in analyzing the teaching tasks, teachers will make judgments on their teaching competence to teach students speaking, listening, reading, and writing in English. Thus, lower efficacy in teaching English would lead teachers to put less effort in motivating students to learn and value English learning (efficacy for engagement). Conversely, if teachers' perceived efficacy in English is high, they will be more likely to engage students in mastery experiences that lead to use English as a means to communicate.

In sum, EFL teachers require adequate preparation not only in grammar, reading, and writing but also in speaking and listening so that they build a strong sense of efficacy to use the language and engage students in learning English through CLT. Finally, although communication-oriented strategies and grammar-oriented strategies were not mutually exclusive, the mean of grammar-oriented strategies was higher indicating the participants' tendency to focus on accuracy over meaning. Data from the interviews supported the teachers' 
reliance on grammar as the focus of English teaching. Teachers reported in the interviews the use of formal lectures, translation, choral and individual repetition, and memorization of dialogues. Under this approach, students are more likely to achieve accuracy than oral fluency. This finding corroborates other studies (Li, 1998; Sato, 2002; Sato \& Kleinsasser, 1999) conducted in Korea, Japan, and Australia with English and Japanese language teachers for whom grammar was the central focus of their teaching.

\section{Conclusion}

The results from the present study indicate positive relationships between teachers' sense of efficacy and language proficiency. The more proficient the participants judged themselves across the four skills, the higher their sense of efficacy. In light of Bandura's (1997) theory, this finding is important because teachers' judgments about their teaching competence influence EFL teachers' practice in terms of efforts, goals, and challenges they set up for themselves and for their students.

Implications: Evidence in this study about the relationship between teacher self-efficacy and English language proficiency highlights the importance of preparing EFL teachers who are competent across the four skills (listening, speaking, reading, and writing). The implications for the education of EFL teachers suggest that English competency to speak, listen, read, and write leads to build a strong sense of efficacy. Because perceived efficacy is task specific, it can be argued that without the communicative competence to perform across the four language skills, many EFL teachers may find themselves unable to use CLT in the English class. Moreover, along with mastery experiences, EFL teachers require vicarious experiences through modeling and observing effective teachers as powerful sources that contribute to increase a stronger self-efficacy.

Finally, although the findings in this study are based on self-reported data, which implies certain built-in limitations, they do provide a foundation for further research about teacher efficacy and
EFL teaching. More studies are needed to elaborate on the sources of information EFL teachers use to build self-efficacy.

\section{Appendix A}

Please read through the following strategies being used in four different EFL classrooms. What do you think about the strategy being used by each EFL teacher? Let us say hypothetically that you use this type of strategy in your English class. Please tell me:

- How would your students have reacted?

- What difficulties would you have faced?

- What assets/challenges could you have predicted with your students?

Classroom 1 (using dialogues): The eighth grade teacher asks students to open their books on page 18 to practice a dialogue. The teacher reads each sentence twice and has students repeat right after. Next, the teacher asks students to translate the expressions in the dialogue helping them when students do not know the meanings. Then, students are paired up to read the dialogue while the teacher circulates around the classroom and corrects students' pronunciation. Finally, volunteer pairs read the dialogue in front of the class.

Classroom 2 (using songs): The seventh grade teacher has students listen to a song while she plays the tape. Students listen to and follow the song on a handout. After, the teacher asks questions to check students' comprehension. The teacher translates the unknown words and has students listen again. Then students are asked to sing the song.

Classroom 3 (using group work in the English class): The seventh grade teacher puts students to work in pairs to write and then simulate a conversation on the phone. Students practice first and then role-play the conversation.

Classroom 4 (using problem-solving in the EFL class): The ninth grade teacher gives her students a problem from everyday life. Then, she asks them to work in small groups to discuss and find possible solutions to the problem being assigned. 
After discussing the problem, one student in each group reports back to the class the consensus reached in solving the problem.

\section{References}

Bandura, A. (1977). Self-efficacy: toward a unifying theory of behavioral change. Psychological Bulletin, 84, 191-215.

Bandura, A. (1993). Perceived self-efficacy in cognitive development and functioning. Educational Psychologist, 28(2), $117-148$.

Bandura, A. (1997). Self-efficacy: the exercise of control. New York: W. H. Freeman and Company.

Brosh, H. (1996). Perceived characteristics of the effective language teacher. Foreign Language Annals, 29(2), 125-138.

Brown, H. D. (1994). Teaching by principles: an interactive approach to language pedagogy. Upper Saddle, NJ: PrenticeHall Regents.

Chacón, C. (2003). Hacia el desarrollo de una práctica pedagógica reflexiva mediante la actualización de los docentes de inglés de la tercera etapa de educación básica: Evaluación de una experiencia [Towards the development of reflective teaching through professional development of middle school English teachers: evaluation of an experience]. Acción Pedagógica, 12(2), 120-129.

Chacón, C., Alvarez, L., Brutt-Griffler, J., \& Samimy, K. K. (2003). Dialogues around "Revisiting the colonial in the postcolonial: Critical praxis for Nonnative-English-speaking teachers in a TESOL program," by Janina Brutt-Griffler and Keiko K. Samimy (1999). In J. Sharkey, \& K. E. Johnson (Eds.), The TESOL quarterly dialogues: rethinking issues of language, culture, and power (pp. 141-150). Alexandria, VA: TESOL.

Coladarci, T. (1992). Teachers' sense of efficacy and commitment to teaching. Journal of Experimental Education, 60(4), 323-337.

Crandall, J. (1999). Aligning teacher education with teaching. TESOL Matters, 9(3), 1-21.

Cullen, R. (1994). Incorporating a language improvement component in teacher training programmes. ELT Journal, $48(2), 162-172$.

Emmer, E. T., \& Hickman, J. (1990). Teacher decision making as a function of efficacy, attributions, and reasoned action. Paper presented at the Annual Meeting of the American Educational Research Association, Boston, MA.

Freeman, D. (1989). Teacher training, development, and decision making: a model of teaching and related strategies for language teacher education. TESOL Quarterly, 23(1), $27-44$.

Ghaith, G., \& Shaaban, K. (1999). The relationship between perceptions of teaching concerns, teacher efficacy, and selected teacher characteristics. Teaching and Teacher Education, 15, 487-496.

Ghaith, G., \& Yaghi, H. (1997). Relationship among experience, teacher efficacy, and attitudes toward implementation of instructional innovation. Teaching and Teacher Education, 13(4), 451-458.

Gibson, S., \& Dembo, M. H. (1984). Teacher efficacy: a construct validation. Journal of Educational Psychology, 76(4), 569-582.

Guskey, T. (1984). The influence of change in instructional effectiveness upon the affective characteristics of teachers. American Educational Research Journal, 21, 245-259.

Guskey, T. (1988). Teacher efficacy, self-concept and attitudes towards the implementation of instructional innovation. Teaching and Teacher Education, 4(1), 63-69.

Guskey, T., \& Passaro, P. (1994). Teacher efficacy: a study of construct dimensions. American Educational Research Journal, 31, 627-643.

Lafayette, R. C. (1993). Subject matter content: what every foreign language teacher needs to know. In G. Gunterman (Ed.), Developing language teachers for a changing world (pp. 124-158). Chicago: National Textbook Company.

Lange, D. L. (1990). A blueprint for a teacher development program. In J. C. Richards, \& D. Nunan (Eds.), Second language teacher education (pp. 245-268). New York: Cambridge University Press.

Larsen-Freeman, D. (2000). Techniques and principles in language teaching (2nd ed). New York: Oxford University Press.

Li, D. (1998). "Its always more difficult than you plan and imagine": teachers' perceived difficulties in introducing the Communicative Approach in South Korea. TESOL Quarterly, 32(4), 677-703.

Ministry of Education, Office of Planning and Budgeting. (1987). Program of study and teacher's manual 7th, 8th, 9th grades third stage basic education subject English, Caracas, September 1987. Caracas capital of Venezuela: Author.

Nunan, D. (1995). Language teaching methodology: a textbook for teachers. New York: Phoenix, ELT.

Pajares, F. (1992). Teachers' beliefs and educational research: cleaning up a messy construct. Review of Educational Research, 62(3), 307-332.

Riggs, I. M., \& Enochs, L. G. (1990). Toward the development of an elementary teacher's science teaching efficacy belief instrument. Science Education, 74(6), 625-637.

Ross, J. A., Cousins, J. B., \& Gadalla, T. (1996). Within-teacher predictors of teacher efficacy. Teaching and Teacher Education, 12, 385-400.

Sato, K. (2002). Practical understandings of Communicative Language Teaching and teacher development. In S. J. Savignon (Ed.), Interpreting communicative language teaching: contexts and concerns in teacher education (pp. 41-81). New Haven, London: Yale University Press.

Sato, K., \& Kleinsasser, R. C. (1999). Communicative language teaching (CLT): practical understandings. The Modern Language Journal, 83, 494-517.

Savignon, S. (1983). Communicative competence: theory and classroom practice. Reading, MA: Addison-Wesley.

Savignon, S. J. (Ed.). (2002). Interpreting Communicative Language Teaching: contexts and concerns in teacher education. New Haven, London: Yale University Press. 
Seidman, I. (1998). Interviewing as qualitative research. New York: Teachers College Press.

Soodak, L. C., \& Podell, D. M. (1997). Efficacy and experience: perceptions of efficacy among preservice and practicing teachers. Journal of Research and Development in Education, 30(4), 214-221.

Spradley, J. P. (1979). Participant observation. New York: Harcourt Brace Jovanich.

Tedick, D. J., \& Walker, C. I. (1995). From theory to practice: how do we prepare teachers for second language classrooms? Foreign Language Annals, 28(4), 499-517.

Tschannen-Moran, M., \& Woolfolk Hoy, A. (2001). Teacher efficacy: capturing an elusive construct. Teaching and Teacher Education, 17, 783-805.
Tschannen-Moran, M., Woolfolk Hoy, A., \& Hoy, W. K. (1998). Teacher efficacy: its meaning and measure. Review of Educational Research, 68(2), 202-248.

Woolfolk, A. E., \& Hoy, W. K. (1990). Prospective teachers' sense of efficacy and beliefs about control. Journal of Educational Psychology, 82(1), 81-91.

Woolfolk Hoy, A., \& Murphy, P. K. (2001). Teaching educational psychology to the implicit mind. In B. Torff, \& R. Sterberg (Eds.), Understanding and teaching the intuitive mind (pp. 145-185). Mahwah, NJ: Lawrence Erlbaum.

Woolfolk, A. E., Rosoff, B., \& Hoy, W. K. (1990). Teachers' sense of efficacy and their beliefs about managing students. Teaching and Teacher Education, 6(2), 137-148. 